\title{
Head injury in a cruise passenger during a shore excursion
}

\section{Eilif Dahl}

Department of Occupational Health, Haukeland University Hospital, the Norwegian Centre for Maritime Medicine, Bergen, Norway

\begin{abstract}
A 66-year-old overweight insulin-dependent male passenger with diabetes and severe arthritis was on a 4-week circle-Pacific cruise. He fell ashore and hit his head. The ship was about to leave on a non-stop voyage - without any evacuation possibilities for the next 8 days. He was examined and had $X$-rays taken at the local hospital, but as his head injury was considered mild, he returned to the ship "for 48 hours of observation for signs of intracranial bleeding" - against the ship's doctor's advice.

Delayed suspicion of a non-displaced cervical fracture caused extra work and worries and could have, but did not complicate matters.

When there are no life-saving therapy and no timely evacuation possibilities in case of deterioration, on-board observation is counterproductive. The patient should be kept in - or near - the local hospital during the necessary observation period, followed by safe repatriation.
\end{abstract}

(Int Marit Health 2016; 67, 3: 161-162)

Key words: head injury, cervical fracture, on-board observation, maritime medicine

\section{CASE REPORT}

A 66-year-old overweight insulin-dependent male passenger with diabetes and severe arthritis was on a 4-week circle-Pacific cruise with his wife. In the last port of call, just before the ship was about to start an 8-day non-stop voyage back to Los Angeles, he went on a shore excursion. At one point he rested without his cane outside the tour bus. When an eager photographer backed toward him, the passenger tried to back out of his way. He stumbled over a raised ledge, fell about $1.5 \mathrm{~m}$ into a hole and hit his head. He was brought on a stiff board by ambulance to the local emergency department where he was diagnosed with a mild brain concussion and multiple contusions. Except for his chronic conditions and a tender swelling with abrasions on the top of his head, clinical examination was unremarkable. $X$-rays of his skull and cervical spine allegedly showed no signs of recent injury.

About an hour prior to the ship's scheduled departure the local emergency physician made a courtesy call to the ship's doctor and reported the history and her findings. The passenger had at that time a moderate headache and "aches and pains all over", but was eager to return to the ship. The emergency physician saw no reason to keep him hospitalised, as his wife, a former nurse practitioner, had agreed to look after him aboard. Because of his recent head injury, he "only needed to be closely watched during the next 48 hours for signs of intracranial bleeding".

The ship's doctor strongly objected: The patient should be monitored in the local hospital for the necessary time, alternatively stay with his wife in a hotel close to the hospital where further emergency diagnostic work-up and treatment could be done or from where he could be airlifted - if necessary. Monitoring on the ship would be of no help because it would be very difficult to turn the megaship back to port if monitoring raised suspicion of increased intracranial pressure, for the next 7 days the ship would be outside helicopter range, and there would be no port within reasonable reach.

At the end of discussion the emergency physician was not entirely convinced, but at that time the ship's departure was imminent, so return to the ship was considered unrealistic.

However, the couple managed to get back to the ship, but medical assistance was not requested.

One day after departure a message arrived from the emergency department: They had reviewed the X-rays and 
now suspected a non-displaced fracture of the second cervical vertebra (C2).

An immediate stateroom call was made; the passenger was immobilised on a long-board with a rigid neck support and brought to the ship's medical centre. New cervical X-rays were taken and sent off for a second opinion by a radiologist ashore. Clinically he was in rather good shape, still with some aches and pains, but he had no neurological deficits and no pronounced neck tenderness.

Immobilisation on a long-board in a hospital bed for a full week would be torture; he would be at high risk of thromboembolic complications, and anticoagulation would be contraindicated because of his head injury.

The radiologist was less than impressed with the ship's cervical X-rays: Only C1, C2 and C3 could be properly visualised; however, no acute osseous injury of those three vertebrae was identified. The passenger could therefore be released from the medical centre with a hard neck collar for further recovery in his own stateroom. The rest of his cruise was uneventful. Upon arrival in Los Angeles he was hospitalised for a thorough diagnostic work-up.

\section{COMMENTS}

The present case concerns a passenger with an unclear head injury, contusions and several complicating chronic conditions. The head injury turned out to be mild, but at the time of release from the emergency department ashore his injury was unresolved to the extent that " 48 hours of observation aboard was recommended".

Monitoring for symptoms of increased intracranial pressure makes hardly any sense on a ship in an area from where the patient cannot be quickly evacuated. In such cases the patient should be kept in - or close to - a hospital ashore, from where he or she can be airlifted if necessary or safely repatriated after an uneventful observation period.
Port physicians who see injured cruise passengers need to inform themselves about the itinerary of the ship to which they intend to return an injured patient. Also, they need to know that helicopters are not available everywhere and that their ranges are limited [1]. Hence, the ship might not be able to evacuate the patient to a modern facility ashore for days. Furthermore, medical centres on even larger cruise vessels cannot be compared to hospitals ashore [2]. Neurosurgical skills are not required aboard cruise ships, nor are cat scans or drills for cranial burr holes listed in the "Health Care Guidelines for Cruise Medical Facilities" of the American College of Emergency Physicians [2].

Neck fractures are almost as feared at sea as intracranial bleedings. In this case delayed suspicion of a non-existent cervical (C2) fracture could have caused complications from week-long neck and body immobilisation, such as severe discomfort and pain, unregulated diabetes, thromboembolism, etc. But fortunately that didn't happen: An incomplete follow-up X-ray examination on board, read by the ship's doctor and confirmed by an independently contracted shoreside radiologist, was good enough to release the patient with just a hard neck collar.

\section{CONFLICTS OF INTEREST}

No financial or material support received. The author has worked as independent ship's doctor and medical consultant for many cruise companies.

\section{REFERENCES}

1. Williams S, Dahl E. Briefing notes on emergency medical disembarks by helicopter at sea in North America. Int Marit Health 2014; 65: 7-12.

2. The American College of Emergency Physicians. Health Care Guidelines for Cruise Ship Medical Facilities (Revised July 2014). https:// www.acep.org/clinical-practice-management/health-care-guidelines-for-cruise-ship-medical-facilities/ (accessed 28 August 2016). 